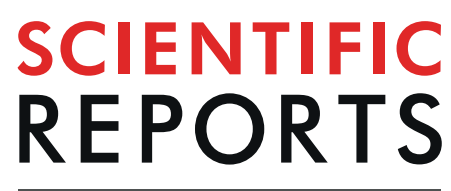

natureresearch

\title{
Immunosuppression response to the neonicotinoid insecticide thiacloprid in females and males of the red mason bee Osmia bicornis L.
}

\begin{abstract}
Annely Brandt ${ }^{1 *}$, Birgitta Hohnheiser ${ }^{1}$, Fabio Sgolastra ${ }^{2}$, Jordi Bosch ${ }^{3}$, Marina Doris Meixner ${ }^{1}$ \& Ralph Büchler ${ }^{1}$

Solitary bees are frequently exposed to pesticides, which are considered as one of the main stress factors that may lead to population declines. A strong immune defence is vital for the fitness of bees. However, the immune system can be weakened by environmental factors that may render bees more vulnerable to parasites and pathogens. Here we demonstrate for the first time that field-realistic concentrations of the commonly used neonicotinoid insecticide thiacloprid can severely affect the immunocompetence of Osmia bicornis. In detail, males exposed to thiacloprid solutions of 200 and $555 \mu \mathrm{g} / \mathrm{kg}$ showed a reduction in hemocyte density. Moreover, functional aspects of the immune defence - the antimicrobial activity of the hemolymph - were impaired in males. In females, however, only a concentration of $555 \mu \mathrm{g} / \mathrm{kg}$ elicited similar immunosuppressive effects. Although males are smaller than females, they consumed more food solution. This leads to a 2.77 times higher exposure in males, probably explaining the different concentration thresholds observed between the sexes. In contrast to honeybees, dietary exposure to thiacloprid did not affect melanisation or wound healing in $O$. bicornis. Our results demonstrate that neonicotinoid insecticides can negatively affect the immunocompetence of $O$. bicornis, possibly leading to an impaired disease resistance capacity.
\end{abstract}

Bees (Anthophila) are important pollinators of wild and cultivated plants, and are therefore essential for ecosystem function and agricultural production ${ }^{1,2}$. Social bee species such as honeybees and bumblebees are most known by scientist and the public. However, the majority of the more than 20,000 bee species worldwide are solitary bees ${ }^{3}$. Honeybees form colonies with a single egg-laying queen and thousands of sterile workers that cooperate with nest building, foraging and brood care. Whereas in solitary bee species the female bee builds and provisions her nest and raises her offspring alone, without the cooperation with others ${ }^{4,5}$. Traditionally most pollination service has been attributed to honeybees or bumblebees, but also solitary bee species contribute significantly to the pollination of wild and cultivated plants ${ }^{1,2}$. Worldwide, managed honeybees and bumblebees are utilized to provide pollination service for food crops, but solitary can pollinate some crops more effectively, thereby promoting the fruit set and increasing the overall crop yield ${ }^{2}$.

Over the past decades, serious declines in bee abundance and diversity have been reported in Europe and Northern America ${ }^{6-8}$. Multiple factors, such as habitat degradation, poor nutrition, parasites, pathogens, and pesticides, acting alone or in combination have contributed to these declines. Among pesticides, the use of neonicotinoid insecticides has been highlighted as an important factor underlying bee losses ${ }^{9-12}$. Neonicotinoids act as agonists of the nicotinic acetylcholine receptor, thus disrupting the neuronal cholinergic signal transduction, which results in abnormal behaviour, immobility and death of target pest insects. Beneficial insects such as bees can be exposed through ingestion of contaminated pollen and nectar of treated plants ${ }^{13-15}$.

Harmful sublethal effects of orally ingested neonicotinoids on honeybees (Apis mellifera L. ${ }^{16}$, bumblebees (Bombus spp. $)^{17}$, and solitary bees ${ }^{12,18-21}$ have been reported in numerous laboratory and field trials, raising concerns over their widespread use and the potential threat to valuable pollination services for crops and wild plants ${ }^{6}$. So far, the majority of studies have focused on three neonicotinoid insecticides commonly used as seed dressings: imidacloprid, thiamethoxam and clothianidin. These insecticides are now considered to pose a serious risk to

${ }^{1}$ LLH Bee Institute, Erlenstr. 9, 35274, Kirchhain, Germany. 'Dipartimento di Scienze e Tecnologie Agro-Alimentari, Università di Bologna, Bologna, Italy. ${ }^{3}$ CREAF, Bellaterra, 08193, Spain. *email: annely.brandt@llh.hessen.de 


\begin{tabular}{|l|l|l|l|l|l|}
\hline Sex & Treatment & $\begin{array}{l}\text { Thiacloprid } \\
\text { concentration }\end{array}$ & $\begin{array}{l}\text { Sugar solution } \\
\text { consumed }(\mathbf{m g} / \mathbf{b e e})\end{array}$ & $\begin{array}{l}\text { Thiacloprid } \\
\text { consumed }(\boldsymbol{\mu g} / \mathbf{b e e})\end{array}$ & $\begin{array}{l}\text { Thiacloprid dosage } \\
(\mathbf{n g} / \mathbf{m g} \text { body weight })\end{array}$ \\
\hline Males & control & 0 & $171.55 \pm 15.32$ & 0.000 & 0.00 \\
\hline & 100 & $100 \mu \mathrm{g} / \mathrm{kg}$ & $179.80 \pm 23.89$ & 0.018 & 0.35 \\
\hline & 200 & $200 \mu \mathrm{g} / \mathrm{kg}$ & $130.95 \pm 25.17$ & 0.026 & $\mathbf{0 . 5 0}$ \\
\hline & 555 & $555 \mu \mathrm{g} / \mathrm{kg}$ & $128.45 \pm 19.17$ & 0.072 & 1.34 \\
\hline Females & control & 0 & $97.22 \pm 22.3$ & 0.000 & 0.00 \\
\hline & 100 & $100 \mu \mathrm{g} / \mathrm{kg}$ & $79.06 \pm 18.42$ & 0.008 & 0.09 \\
\hline & 200 & $200 \mu \mathrm{g} / \mathrm{kg}$ & $80.46 \pm 23.39$ & 0.016 & 0.18 \\
\hline & 555 & $555 \mu \mathrm{g} / \mathrm{kg}$ & $85.88 \pm 17.55$ & 0.046 & $\mathbf{0 . 5 2}$ \\
\hline
\end{tabular}

Table 1. Consumption (mean \pm standard error) of sugar solution over three days, thiacloprid uptake per bee and per mg of body weight in males and females. The thiacloprid dosage per body weight of males in treatment 200 is approx. the same as in females in treatment 555 (bold).

bees, and their use in the European Union has been restricted since $2013^{22}$. However, other neonicotinoids, such as thiacloprid and acetamiprid, are classified as not dangerous for bees, and in some regions or countries are frequently applied to flowering crops when bees are actively foraging ${ }^{23}$. Their potential effects on bees have been largely overlooked, even though thiacloprid and acetamiprid were shown to cause sublethal impairments to bees under agronomically realistic conditions ${ }^{16,24-26}$.

Sublethal exposure to agricultural pesticides has long been acknowledged to have ecologically relevant effects on bees ${ }^{16,23,27}$. However, potential effects on immune function and disease resistance have only recently been recognized $^{28,29}$. Compromised immunity caused by exposure to neonicotinoids has been demonstrated in honeybees $^{25,26,30}$ and bumblebees ${ }^{28}$, but information on solitary bees is largely missing. Honeybee exposure to neonicotinoids has been associated with negatively modulated immune signalling and increased virus replication ${ }^{30}$, with reduced hemocyte numbers, wound healing, and cellular responses to bacterial infection ${ }^{25,26,31}$, and with reduced activity of an enzyme involved in social immune food sterilisation ${ }^{32}$. In bumblebees, exposure to high doses of imidacloprid reduced constitutive levels of phenoloxidase ${ }^{28}$. Investigating the immune response of other bee taxa is important for three reasons. First, several studies have shown that different bee species may have different sensitivities to pesticides ${ }^{18,33-38}$. Second, different bee species may show differences in routes and levels of pesticide exposure $^{39,40}$. Third, social bees are considered less vulnerable to pesticides, because effects at the individual level can be buffered by the colony (colony resilience ${ }^{41}$ ). These inter-specific differences have underscored the need to include several bee species in pesticide risk assessment schemes ${ }^{18,19,41,42}$.

Two Osmia species, Osmia cornuta and O. bicornis have been proposed as model species by the EFSA Guidance Document on the risk assessment of plant protection products on solitary bees ${ }^{43}$. Most bee risk assessment schemes and ecotoxicological studies focus on females ${ }^{43}$. However, assessing the effects of pesticides on males is important for two reasons. First, in the vast majority of bee species, including all solitary species, males are also exposed to pesticides via nectar ingestion. Second, sex-specific differences in humoral immune parameters have been described for two solitary bee species ${ }^{44,45}$. For these reasons, we decided to investigate potential response differences between the sexes.

In this study, we investigate potential differences between the sexes in the immune response of a solitary bee, the red mason bee, Osmia bicornis L. (syn. Osmia rufa L.) to oral ingestion of thiacloprid. The objectives of our study are: (1) To describe functional parameters (hemocyte density, antimicrobial activity of the hemolymph, and melanisation response) of the immune system; (2) To examine, whether these parameters are affected by orally ingested sublethal concentrations of thiacloprid; (3) To compare the responses of males and females.

\section{Results}

Food consumption. Bees of both sexes consumed low amounts of sugar solution the first two days of exposure, but uptake increased on day three. Although females are heavier than males (Suppl. Figure 1), they consumed less feeding solution (Table 1). Hence, the total thiacloprid dosage of males in treatment 200 was 2.77 times higher than that of females. Based on these results, additional experiments with adjusted concentrations of $555 \mu \mathrm{g} / \mathrm{kg}$ thiacloprid were performed to reach a similar dosage per mg body weight in females as in males of the treatment 200 group.

Pollen consumption was observed in both males and females. However, it was difficult to quantify because bees spread crumbles of the pollen patty all over the cage.

Total hemocyte counts. In males, a reduction in the total number of hemocytes was observed in the treatment groups 200 and 555 (Fig. 1a, Kruskal-Wallis test, KWT, p =0.001; Mann-Whitney U test, MWU, control ${ }_{2016}$ vs. treatment 200, $\mathrm{p}=0.001$; Fig. 1 b, KWT, $\mathrm{p}<0.001$; $\mathrm{MWU}_{\text {, control }}{ }_{2018}$ vs. treatment $555, \mathrm{p}<0.001$, additional statistical information in Table 1). However, in females, the exposure to 100 or $200 \mu \mathrm{g} / \mathrm{kg}$ thiacloprid did not significantly reduce the total hemocyte counts (Fig. 1c, KWT, $\mathrm{p}=0.187$ ). Only when we exposed females to $555 \mu \mathrm{g} /$ $\mathrm{kg}$ (comparable to the dosage/mg body weight ingested by males in treatment 200 ), we observed a significantly reduced number of hemocytes (Fig. 1d, KWT, $\mathrm{p}<0.001$; post-hoc $\mathrm{MWU}$ control ${ }_{2018}$ vs. treatment $555, \mathrm{p}<0.001$ ). Unexpectedly, the total number of hemocytes differed between the years ( $\operatorname{control}_{2016}$ vs. control $_{2018}$ : females, MWU, $\mathrm{p}<0.001$; males, MWU, $\mathrm{p}=0.004)$. 
a

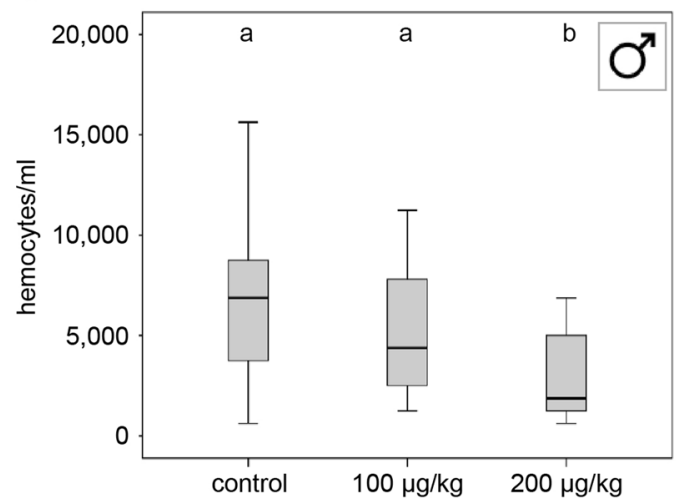

C

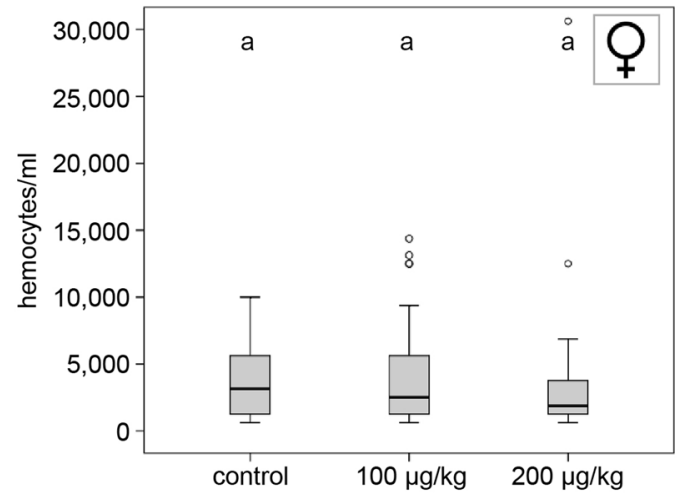

b

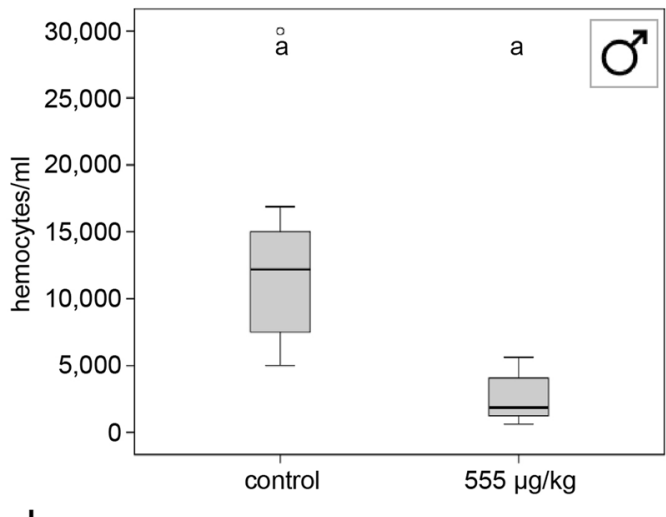

d

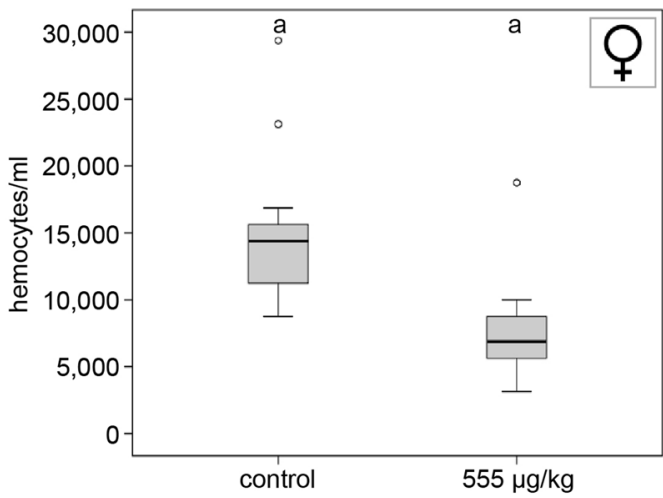

Figure 1. Hemocyte counts in males and females in relation to thiacloprid concentration of feeding solution (a,b) Males exposed to $200 \mu \mathrm{g} / \mathrm{kg}$ thiacloprid showed a significantly reduced total number of hemocytes (control, $\mathrm{n}=21 ; 100 \mu \mathrm{g} / \mathrm{kg}, \mathrm{n}=23 ; 200 \mu \mathrm{g} / \mathrm{kg}, \mathrm{n}=21$; Kruskal-Wallis test, $\mathrm{p}<0.0001$; post-hoc Mann-Whitney test, control vs. $200 \mu \mathrm{g} / \mathrm{kg}, \mathrm{p}=0.001$; control vs. $555 \mu \mathrm{g} / \mathrm{kg}, \mathrm{p}<0.0001$ ). (c) Hemocyte density of females exposed to 100 or $200 \mu \mathrm{g} / \mathrm{kg}$ thiacloprid showed no differences from control (control, $\mathrm{n}=32 ; 100 \mu \mathrm{g} / \mathrm{kg} \mathrm{n}=34 ; 200 \mu \mathrm{g} / \mathrm{kg}, \mathrm{n}=34$; Kruskal-Wallis test, $\mathrm{p}=0.187$ ). (d) Exposure to $555 \mu \mathrm{g} / \mathrm{kg}$ resulted in reduced hemocyte density in females (control, $\mathrm{n}=18 ; 555 \mu \mathrm{g} / \mathrm{kg}, \mathrm{n}=17$; Mann-Whitney test, $\mathrm{p}=0.004$ ). Whiskers encompass $95 \%$ of the individuals, beyond which outliers (circles reside). Treatments with different letters differ significantly from each other.

Antimicrobial activity of the hemolymph. The size of the inhibition zones was significantly reduced in

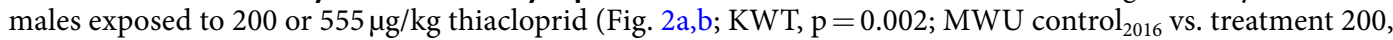
$\mathrm{p}=0.0008$; control $_{2018}$ vs. treatment $555, \mathrm{p}<0.001$; additional statistical information in Table 1). The antimicrobial activity was not significantly reduced in females exposed to 100 or $200 \mu \mathrm{g} / \mathrm{kg}$ thiacloprid (Fig. 2c; KWT, $\mathrm{p}=0.454$ ). Only females exposed to $555 \mu \mathrm{g} / \mathrm{kg}$ thiacloprid showed significantly reduced inhibition zones (Fig. 2d, MWU, control 2018 vs. treatment $555, \mathrm{p}<0.001$ ).

In some individuals, the injection procedure obviously caused some damage, especially males where affected, probably because the handling of the smaller males is more difficult. In some bees, the movement of the hindlegs where impaired, some died. These affected individuals were censored and excluded from the measurements (females: control $=17 \%$; treatment $100=11 \%$; treatment $200=16 \%$; males: control $=32 \%$; treatment $100=31 \%$; treatment $200=20 \%$ ). There was no statistically significant difference between the treatment groups.

We tested the effect different experimenters have on the variance of the inhibition zone diameters using Lysozyme as a standard. Interestingly, we found a significant statistical difference between the measurements of inhibition zone diameters done by two persons (Suppl. Table 2). Therefore, only a single person pipetted the hemolymph and measured the inhibition zone to increase the technical repeatability of the assay.

Encapsulation response. The encapsulation response to thiacloprid exposure was not significantly reduced in males (Fig. 3a; KWT, p = 0.295) or females (Fig. 3b; KWT, $\mathrm{p}=0.303$; additional statistical information in Table 1).

\section{Discussion}

We demonstrate that the commonly used neonicotinoid insecticide thiacloprid impairs the immune defence of a solitary bee, Osmia bicornis. The number of hemocytes, as well as the antimicrobial activity of the hemolymph, were negatively affected by sublethal, environmentally relevant concentrations of thiacloprid. Although males are smaller than females, they consumed significantly more food than females. This leads to higher exposure in males 
a

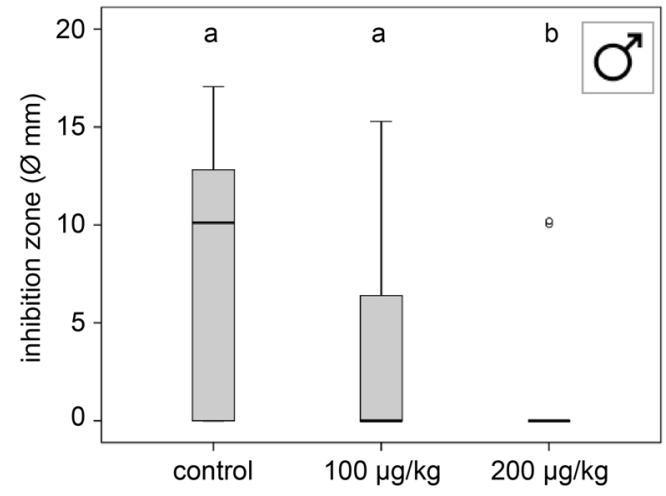

C

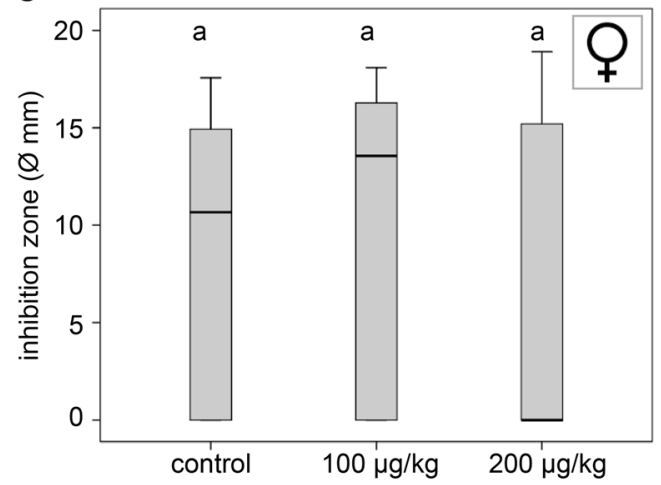

b

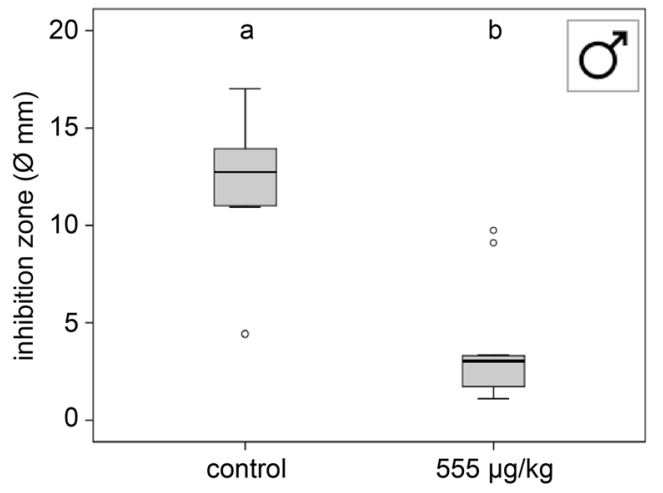

d

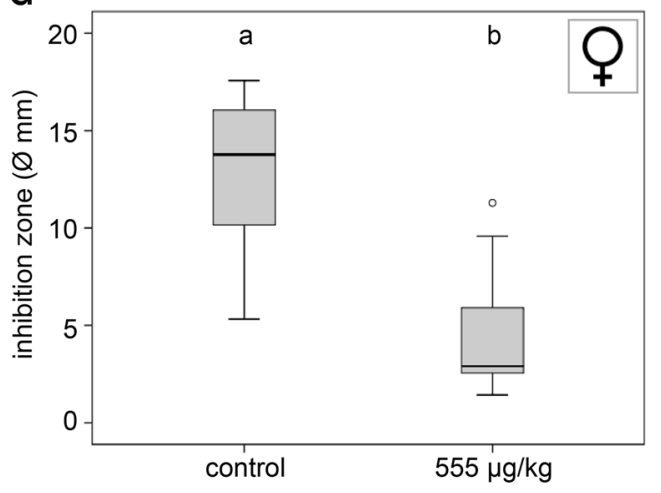

Figure 2. Antimicrobial activity of hemolymph of males and females in relation to thiacloprid concentration of feeding solution. (a,b) The diameters of inhibition zones were significantly reduced in males exposed to thiacloprid (control, $\mathrm{n}=26 ; 100 \mu \mathrm{g} / \mathrm{kg}, \mathrm{n}=19 ; 200 \mu \mathrm{g} / \mathrm{kg}, \mathrm{n}=22$; Kruskal-Wallis test, $\mathrm{p}=0.002$; post-hoc MannWhitney test, control vs. $200 \mu \mathrm{g} / \mathrm{kg}, \mathrm{p}=0.0008$ ). (c) Females exposed to lower concentrations of thiacloprid showed no effect on antimicrobial activity (control, $\mathrm{n}=30 ; 100 \mu \mathrm{g} / \mathrm{kg}, \mathrm{n}=25 ; 200 \mu \mathrm{g} / \mathrm{kg}, \mathrm{n}=33$; KruskalWallis test, $\mathrm{p}=0.454)$. (d) The inhibition zone diameters of the haemolymph of females exposed to the highest concentration $(555 \mu \mathrm{g} / \mathrm{kg}$ ) were significantly reduced (control, $\mathrm{n}=13 ; 555 \mu \mathrm{g} / \mathrm{kg}, \mathrm{n}=16$; Mann-Whitney test, $\mathrm{p}>0.0001$ ). Whiskers encompass $95 \%$ of the individuals, beyond which outliers (circles reside). Treatments with different letters differ significantly from each other.

even at field-realistic concentrations of thiacloprid, probably explaining the different concentration thresholds observed between the sexes. In contrast to honeybees, dietary exposure to thiacloprid did not affect the melanisation or wound healing response in O. bicornis.

Thiacloprid is generally regarded as non-harmful to bees based on its relatively low acute toxicity to honeybees (oral acute $\mathrm{LD} 50_{48 \mathrm{~h}}=17.32 \mu \mathrm{g} / \mathrm{honeybee}^{46}$ ). The thiacloprid concentrations we used fall within the range of concentrations found in field situations. In pollen collected by honeybees, mean thiacloprid residues were $75.1 \mu \mathrm{g} / \mathrm{kg}$ ( $\max .: 1002 \mu \mathrm{g} / \mathrm{kg}$, mean prevalence of $17.7 \%$ ) and $6.5 \mu \mathrm{g} / \mathrm{kg}$ in honey (max.: $208 \mu \mathrm{g} / \mathrm{kg}, 64 \%$ prevalence ${ }^{47}$ ). In the German bee monitoring project, the highest concentration of thiacloprid in beebread samples was $498 \mu \mathrm{g} / \mathrm{kg}^{48}$.

In general, hemocytes are the key components of the cellular immune defence of insects. They are responsible for phagocytosis or encapsulation of pathogens as well as for wound closure ${ }^{49,50}$. On average, female O. bicornis had lower total hemocyte counts than males. Interestingly, only the highest concentration of $555 \mu \mathrm{g} / \mathrm{kg}$ thiacloprid reduced the hemocyte density in females. In contrast, we found a reduction of hemocyte number in males dosed as low as with $200 \mu \mathrm{g} / \mathrm{kg}$, indicating a disturbance of the immune system after exposure to concentrations frequently found under field conditions ${ }^{48}$. This reduction of hemocytes in neonicotinoid-exposed O. bicornis could limit the capacity of the red mason bees to mount a rapid immune response $\mathrm{e}^{51}$.

One essential functional aspect of the bee's immune system is the induced immunity as measured by the humoral antimicrobial activity of the hemolymph. The humoral immune response is mediated by antimicrobial peptides that are produced by hemocytes and fat body cells. These are biologically active molecules with antibacterial, antifungal, or antiviral properties ${ }^{50,52}$. Together with the reduction of hemocyte density, the reduced antimicrobial activity in thiacloprid-exposed males $(200$ and $555 \mu \mathrm{g} / \mathrm{kg})$ and females $(555 \mu \mathrm{g} / \mathrm{kg})$ could likely impair the immune strength of $O$. bicornis and increase their susceptibility towards pathogens.

In insects, hemocytes actively encapsulate infected cells or intruding pathogens and migrate to wounds in order to close them. Concurrently, hemocytes produce prophenoloxidase, the precursor of the enzyme phenoloxidase, which catalyses the melanisation reaction ${ }^{50}$. In both female and male O. bicornis, a melanisation reaction of an implanted nylon fibre was observed. However, contrary to findings in A. mellifera workers ${ }^{26}$ and queens $s^{25}$, 

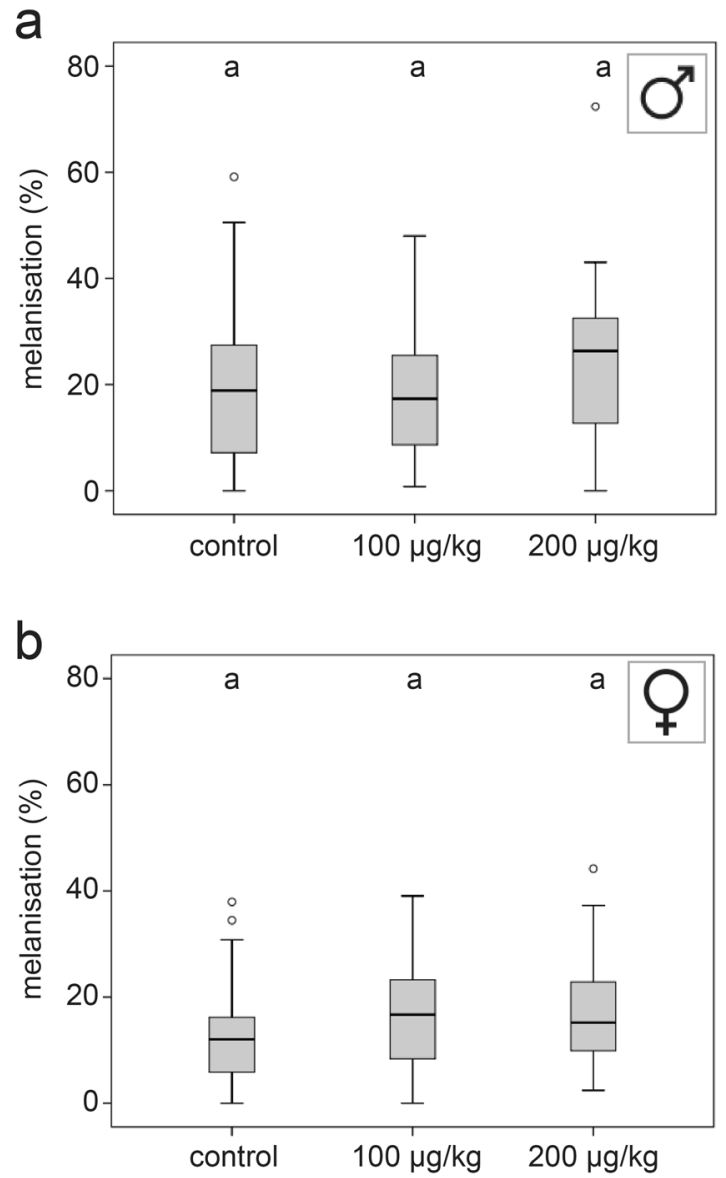

Figure 3. Exposure to thiacloprid had no effect on the melanisation response. The three day-exposure of young males (a; control, $\mathrm{n}=22 ; 100 \mu \mathrm{g} / \mathrm{kg}, \mathrm{n}=26 ; 200 \mu \mathrm{g} / \mathrm{kg}, \mathrm{n}=27 ;$ Kruskal-Wallis test, $\mathrm{p}=0.295)$, and females $(\mathbf{b})$ had no effect on the melanisation of an implanted nylon filament compared to control (control, $\mathrm{n}=22 ; 100 \mu \mathrm{g} / \mathrm{kg}$, $\mathrm{n}=26 ; 200 \mu \mathrm{g} / \mathrm{kg}, \mathrm{n}=27$; Kruskal-Wallis test, $\mathrm{p}=0.303$ ). Whiskers encompass $95 \%$ of the individuals, beyond which outliers (circles reside). Treatments with different letters differ significantly from each other.

where thiacloprid significantly reduced the melanisation response, no reduction was observed in O. bicornis. This finding may reflect differences in the pathogen and parasite pressure of these two species. In contrast to $O$. bicornis, honeybees have co-evolved with hemolymph sucking parasites (Acarapis woodi, Tropilaelaps spp., and recently Varroa destructor) which might explain this divergence between O. bicornis and A. mellifera. Our results emphasise the need to test different species and not to generalize the findings of honeybee studies to other bee species.

Solitary bees have evolved under a different selective pressure than social bees like honey bees or bumble bees, which have evolved specific behavioural, physiological, and organizational adaptations to combat the increased risk of disease inside a colony ${ }^{51,53}$. Hence, the variation in pathogen-specific selective pressure may result in immunocompetence dissimilarities across species.

A comparative analysis about the immune system and the effects of pesticide stressors on immune strength of bee species is difficult since comprehensive information is even missing for honeybees and much more for solitary bees. Genomic analysis of honeybees shows that the basic set of molecules defining the insect immune system is present. However, compared to the sequenced Drosophila and Anopheles genomes, honeybees possess only about one-third as many genes implicated in insect immunity ${ }^{50}$. This has been related to the eusociality of honeybees. It has been hypothesised that honey bees do not need a more diverse immune repertoire since they are confronted to a less diverse, co-evolved, set of pathogens and that social defence mechanisms, like grooming or brood hygiene lessen the pathogen pressure ${ }^{50}$. Since solitary bee species have no social defence mechanisms, it has been expected that they have a more diverse immune repertoire than eusocial bees ${ }^{44}$. Strachecka et al. investigated the chemical defence mechanisms of red mason bees. Indeed, O. bicornis had generally higher activities and concentrations of defence compounds in the hemolymph than eusocial bees ${ }^{44}$. However, since the genomes of solitary bee species have not yet been sequenced, it is not possible to compare the genes implicated in immunity to further substantiate this hypothesis.

Neonicotinoids have been shown to affect the immunocompetence of honeybees. Like in O. bicornis, thiacloprid has been shown to reduce the hemocyte density, especially the proportion of active, differentiated immune cells in honeybees as well as the antimicrobial activity of the hemolymph ${ }^{25,26}$. Neonicotinoids negatively modulate $\mathrm{NF}-\kappa \mathrm{B}$ immune signalling and promote the replication of deformed wing virus ${ }^{30}$. Moreover, thiacloprid increases 
the mortality of Nosema ceranae infected honeybees ${ }^{54}$. Whether neonicotinoids affect the disease susceptibility of O. bicornis remains to be elucidated.

The observed differences in immunocompetence between male and female O. bicornis are likely related to the differences in food uptake, resulting in unequal exposure levels. Indeed, we observed huge differences in absolute food uptake between females and males across all four treatments. For example, males of the 200 treatment consumed $0.5 \mathrm{ng}$ thiacloprid per $\mathrm{mg}$ body weight, whereas females consumed only $0.18 \mathrm{ng} / \mathrm{mg}$. After including an additional higher concentration of $555 \mu \mathrm{g} / \mathrm{kg}$, to account for these differences, reduction of immunocompetence was also observed in females.

The higher food consumption of males can be explained by behavioural differences between the sexes in the post-emergence phase. On average, males emerge 2-4 days before females. They actively patrol nesting sites and try to mate with emerging females, most of which are mated right upon emergence. Once mated, newly emerged females typically hide in crevices and undergo a 2-5-day pre-nesting period, during which they complete ovary maturation ${ }^{5}$. We observed similar behavioural patterns in our experimental flight cages where males were flying and walking extensively, whereas females were mostly hiding in the artificial nesting tubes.

Interestingly, sex-specific differences in immune parameters of O. bicornis ${ }^{44}$ and Megachile rotundata ${ }^{45}$ were previously reported, indicating lower concentrations and activity levels of phenoloxidase and alkaline phosphatase, and of enzymatic and non-enzymatic antioxidant and proteolytic systems in males. Based on our experimental data, we cannot determine whether physiological or behavioural differences that result in different exposure levels or both caused the divergent immunosuppressive effects between the sexes.

The current risk assessment scheme for the approval and authorization of pesticides focuses on A. mellifera, implicating that data obtained with honey bees can be extrapolated to other bee species without considering inter-specific differences ${ }^{18}$. A. mellifera is generally considered as extremely sensitive to pesticides and a good indicator species for environmental pollution ${ }^{55,56}$. However, the extrapolation of a risk assessment to other bees may not be appropriate. The response to pesticides and the differences in the level of exposure may vary significantly between bee taxa $a^{38,43}$ making it difficult to predict which bee species are more or less susceptible to pesticides $^{15}$. Indeed, our results indicate clear differences between red mason bees and honeybees and emphasize the need for comparative studies and independent pesticide risk assessment procedures for non-Apis bees.

Currently, only the food intake of adult females is considered as relevant; while food intake of adult male is regarded "not relevant" or unknown ${ }^{43,57}$. However, our results show clear sex-specific differences in food uptake and exposure level and - most likely as a consequence - an elevated response of males towards field realistic thiacloprid concentrations. Therefore, male bees should be included in future risk assessment schemes for approval and authorization of pesticides.

The interaction of pathogens and pesticides is of grave concern in relation to pollinator health. Multiple stressors on bee health act not in isolation, but rather interact, with possible synergistic effects on bees and bee populations $^{8,58}$. Our findings highlight the importance of including non-Apis species and both sexes in eco-toxicological studies and risk assessment procedure ${ }^{27}$. This has also a strong economic and ecological relevance since many bee species, other than A. mellifera, contribute decisively to crop and wild plant pollination ${ }^{2}$.

\section{Methods}

Osmia bicornis population management. Osmia bicornis cocoons reared at the arboretum of the Botanical Garden of the University of Rostock (Germany) were obtained from Johann-Christoph Kornmilch (bienenhotel.de, Rostock, Germany). The cocoons were shipped in January and stored in the dark at $4^{\circ}-7^{\circ} \mathrm{C}$. To induce adult emergence, cocoons were placed in cages $(30 \times 30 \times 30 \mathrm{~cm}$, Aerarium, bioform, Nürnberg, Germany) under natural light at room temperature ( $1^{\text {st }}$ of March $-4^{\text {th }}$ of May 2016 and 2018; average temperature $22.6^{\circ} \mathrm{C}$, min $20.0^{\circ} \mathrm{C}$, max. $24.2^{\circ} \mathrm{C}$; relative humidity $62 \%$, min. $58.8 \%$, max. $72 \%$, datalogger EL-USB-2, Lascar electronics, Whiteparish). We separated female and male cocoons based on size, and kept them in separate cages for the whole study. Approximately 24 hours after emergence, we transferred the bees to new cages in groups of 5 to 10 individuals, where the exposure to thiacloprid took place. We conducted three independent replicates (cages) per treatment and sex for each immune assay.

Test solutions. A stock solution of $2 \mathrm{mg} / \mathrm{ml}$ thiacloprid (Sigma Aldrich, St. Louis, USA; purity $99.9 \%$ ) in acetone was prepared in a glass flask and stored in the dark at $15^{\circ} \mathrm{C}$ until use. The stock solution was added to a $50 \%$ feeding solution of invert sugar (Ambrosia, Germany) in distilled water (w/v) to reach three test concentrations: 100,200 , and $555 \mu \mathrm{g} / \mathrm{kg}$ (henceforward referred to as treatment 100, 200 and 555). The final concentration of acetone in the test solutions was adjusted to $0.0086 \%$ (v:v) in all treatments.

A pollen patty was prepared from pollen collected by honey bees at the Bee Institute Kirchhain or obtained from Imkereibedarf Bährle (Aschaffenburg, Germany). The pollen was stored at $-20^{\circ} \mathrm{C}$ for $8-10$ months and then pulverized in a coffee grinder. The resulting pollen powder was mixed with the thiacloprid-spiked feeding solution to obtain the same concentrations as the feeding solution $(100,200,555 \mu \mathrm{g}$ of thiacloprid per kg of pollen patty).

Neonicotinoid exposure. Test cages were placed close to each other $(\sim 2 \mathrm{~cm})$, so bees of both sexes could see, hear and smell each other. Fragments of egg carton and $5 \mathrm{~cm}$ segments of black plastic drinking straws were placed in each flight cage as hiding sites. Cages were kept at room temperature under natural light conditions.

Caps of $1.5 \mathrm{ml}$ microcentrifuge tubes (Eppendorf, Hamburg, Germany) were cut off and used as containers for the feeding solution (two caps per cage) and pollen paste (two caps per cage). The bottoms of the caps were coloured red or blue and placed on a green piece of cardboard to attract the bees. Both females and males found the food sources immediately, and feeding was observed frequently. 


\begin{tabular}{|c|c|c|c|c|c|}
\hline \multirow{2}{*}{$\begin{array}{l}\text { Immune parameter } \\
\text { mean } \pm \text { s.e.m, } n=\text { number of } \\
\text { individuals }\end{array}$} & \multicolumn{3}{|c|}{ Experiments in 2016} & \multicolumn{2}{|l|}{ Experiments in 2018} \\
\hline & Control & $100 \mu \mathrm{g} / \mathrm{kg}$ & $200 \mu \mathrm{g} / \mathrm{kg}$ & Control & $555 \mu \mathrm{g} / \mathrm{kg}$ \\
\hline \multicolumn{6}{|l|}{ Males } \\
\hline Total hemocyte count (cells/ml) & $6815.48 \pm 782.81$ & $5135.87 \pm 596.54$ & $2946.43 \pm 437.70$ & $12109.38 \pm 1496.53$ & $2708.33 \pm 699.29$ \\
\hline$n$ & 21 & 23 & 21 & 16 & 15 \\
\hline Inhibition zone $(\mathrm{mm})$ & $7.02 \pm 2.88$ & $3.59 \pm 1.04$ & $0.92 \pm 1.39$ & $12.42 \pm 3.10$ & $3.33 \pm 0.86$ \\
\hline$n$ & 26 & 19 & 22 & 16 & 15 \\
\hline \multicolumn{6}{|l|}{ Censored individuals } \\
\hline \multirow[t]{2}{*}{ Encapsulation (\% grey value) } & $20.26 \pm 3.42$ & $18.66 \pm 2.46$ & $24.39 \pm 2.94$ & - & - \\
\hline & 22 & 26 & 27 & & \\
\hline \multicolumn{6}{|l|}{ Females } \\
\hline Total hemocyte count (cells/ml) & $3574.22 \pm 457.41$ & $4264.71 \pm 691.95$ & $3382.35 \pm 916.22$ & $14791.67 \pm 1121.91$ & $8198.53 \pm 1010.70$ \\
\hline$n$ & 32 & 34 & 34 & 18 & 17 \\
\hline Inhbition zone $(\mathrm{mm})$ & $8.12 \pm 1.23$ & $9.48 \pm 1.56$ & $6.81 \pm 1.39$ & $13.6 \pm 3.62$ & $4.33 \pm 1.08$ \\
\hline$n$ & 30 & 25 & 33 & 13 & 16 \\
\hline Encapsulation (\% grey value) & $13.44 \pm 1.86$ & $16.44 \pm 1.98$ & $17.37 \pm 1.91$ & - & - \\
\hline$n$ & 22 & 26 & 27 & & \\
\hline
\end{tabular}

Table 2. Results of immune test and number of individuals per treatment group and sex for each experiment, at least three independent test runs were conducted. The total number of males and females $(n)$ included in data analysis is given for each experiment (s.e.m = standard error of the means).

Each cage was assigned to one of four thiacloprid treatments and exposed for three days. Feeding caps were weighed and renewed every day. For each treatment group and sex, three cages of 6 to 10 individuals were set up on independent dates. In 2016, we tested the 0,100 and $200 \mu \mathrm{g} / \mathrm{kg}$ treatments (Table 2). Then, based on the discrepancies observed between the dosage per body weight in males and females, additional experiments with 0 and 555 treatments were conducted (three groups for each treatment and sex on independent dates in 2018) to obtain data on a dosage taken up by females equivalent to the 200 treatment in males (Table 2). In order to minimize the variance in the following functional immune assays caused by different experimenters, only one person at a time analysed the three treatment groups (Suppl. Tables 1 and 2).

Hemolymph extraction and total hemocyte counts. Bees were anesthetized on ice, and hemolymph was extracted by inserting a microinjection needle (Hartenstein, Würzburg, Germany) into the proximal abdomen between the $3^{\text {rd }}$ and $4^{\text {th }}$ tergum ${ }^{25,26}$. Hemolymph $(1 \mu \mathrm{l})$ was transferred to PCR-tubes (Biozym, Hessisch Oldendorf, Germany) containing $1 \mu \mathrm{l}$ of DAPI-staining solution (4'6-diamidino-2-phenylindole; 1:100 dilution, lifetechnologies, Carlsbad, California, USA) and $3 \mu \mathrm{l}$ PBS (pH 7.4; Sigma Aldrich, St. Louis, USA). Hemocytes were counted in a counting chamber (Bürker, Carl Roth, Karlsruhe, Germany) under a phase contrast/fluorescent microscope (Leica DMIL, Leica camera DFC 420 C) ${ }^{25,26}$.

Encapsulation response. A $2.5 \mathrm{~mm}$ nylon filament was partly inserted into the abdomen of anesthetized bees as previously described for honeybees ${ }^{25,26}$. After implantation, females were transferred to $1.5 \mathrm{ml}$ microcentrifuge tubes and males to PCR-tubes with holes poked through the cap and sidewalls. After four hours at room temperature, the nylon filament was extracted, fixed in formaldehyde solution for at least 1 hour, rinsed three times in PBS, and subsequently mounted in glycerol (85\%, Carl Roth). For each explant, three pictures were taken at different focal depths. The mean grey value per filament was calculated using image analysis software and taken as a measure of melanisation ${ }^{59}$. The mean grey value of a non-implanted filament was subtracted from the mean grey value of the implanted filaments ${ }^{25}$.

Antimicrobial response. On day two of the exposure phase, the immune system was challenged by the injection of $1 \mu \mathrm{l}$ of heat-inactivated Escherichia coli (OD 0.5$)^{25,26}$. Hemolymph was collected and stored at $-20^{\circ} \mathrm{C}$. Bacterial test plates $(\varnothing 9 \mathrm{~cm}$ ) were prepared by adding $0.8 \mathrm{ml}$ of live Micrococcus luteus bacteria suspension (OD $0.5)$ to $150 \mathrm{ml}$ of sterile broth medium $\left(48^{\circ} \mathrm{C}, 1.5 \mathrm{~g}\right.$ Agar No. 1, Oxoid; $3.75 \mathrm{~g}$ nutrient broth, Applichem). For each test plate, five holes $(\varnothing 3.33 \mathrm{~mm})$ were punched into the agar with a $1 \mathrm{ml}$ pipette tip, and $1 \mu \mathrm{l}$ of hemolymph solution was added to each hole. Plates were incubated at $38^{\circ} \mathrm{C}$ overnight, and the diameter of inhibition zones was measured with a digital calliper ${ }^{25,26}$.

Repeatability of measurements. To investigate possible sources of variance and estimate the technical repeatability of our functional measurements of hemocyte density, antimicrobial activity of the hemolymph, and melanisation response, we conducted additional experiments. For these experiments, we collected adult Apis mellifera workers from an apparently healthy colony that was not treated against Varroa destructor (December 18 , 2019). For hemocyte counts, we extracted hemolymph as described before ${ }^{26}$. Two experimenters (for details, see Suppl. Table 1) counted the hemocytes of 30 bees independently. Since hemocytes are mobile, we counted the cells as fast as possible. 
For the melanisation response, we implanted and prepared 30 transparent nylon fibres as described before ${ }^{26}$. A single experimenter (Suppl. Table 1) made the microscopic pictures of the same implants twice and conducted the subsequent image analysis independently from each other. To reduce the technical variance, we led the microscope lamp warm up for 30 min before we started to take the pictures.

To estimate for the methodological repeatability of inhibition zone assays, we applied $1 \mu \mathrm{l}$ of a standard solution of lysozyme ( $1 \mathrm{mg} / 1 \mathrm{ml}$, Applichem, Darmstadt, Germany) on M. flavus inoculated petri dishes. To cover different technical sources of variance, we tested three scenarios (a) pipetting done by two persons, (b) measuring of the inhibition zone diameters done by two persons, (c) repeated measurements of the inhibition zone diameters done by a single person.

Statistical methods. All statistical tests were run with SPSS for Windows (v. 20). Total hemocyte counts, melanisation/mean grey values, and mean diameters of inhibition zones were not normally distributed. Thus, non-parametric statistics were applied ${ }^{25,26}$. Each immunocompetence measure was compared across treatments using Kruskal-Wallis tests (KWT) followed by post-hoc pair-wise comparisons with Mann-Whitney U tests (MWU) and Bonferroni corrections (when more than two groups were compared) ${ }^{25,26}$. In order to calculate the repeatability of the functional measurements, we first applied a one-way ANOVA and subsequently calculated the approximate repeatability values from the $\mathrm{F}$ ratio and mean squares among groups/mean squares within groups according to Lessells and Boag ${ }^{60}$.

Ethics. Ethical approval and the licences were obtained from the Hessian Regional Council of Giessen (RPGI), Germany.

\section{Data availability}

The datasets supporting this article have been uploaded as part of the supplementary material.

Received: 8 July 2019; Accepted: 28 January 2020;

Published online: 13 March 2020

\section{References}

1. Klein, A.-M. et al Importance of pollinators in changing landscapes for world crops, (2007).

2. Garibaldi, L. A. et al. Wild pollinators enhance fruit set of crops regardless of honey bee abundance. Sci. 339, 1608-1611, https://doi. org/10.1126/science.1230200 (2013).

3. Azpiazu, C. et al. Chronic oral exposure to field-realistic pesticide combinations via pollen and nectar: effects on feeding and thermal performance in a solitary bee. Sci. Rep. 9, 13770, https://doi.org/10.1038/s41598-019-50255-4 (2019).

4. Robinson, G. E., Winston, M. L., Huang, Z. \& Pankiw, T. Queen mandibular gland pheromone influences worker honey bee (Apis mellifera L.) foraging ontogeny and juvenile hormone titers. J. insect Physiol. 44, 685-692 (1998).

5. Bosch, J., Sgolastra, F. \& Kemp, W. P. In Bee Pollination in Agricultural Ecosystems (eds Rosalind R. James \& Theresa L. Pitts-Singer) Ch. 6, 83-104 (Oxford University Press (2008).

6. Potts, S. G. et al. Global pollinator declines: trends, impacts and drivers. Trends Ecol. evolution 25, 345-353, https://doi.org/10.1016/j. tree.2010.01.007 (2010).

7. vanEngelsdorp, D. \& Meixner, M. D. A historical review of managed honey bee populations in Europe and the United States and the factors that may affect them. J. invertebrate Pathol. 103, S80-S95, https://doi.org/10.1016/j.jip.2009.06.011 (2010).

8. Goulson, D., Nicholls, E., Botias, C. \& Rotheray, E. L. Bee declines driven by combined stress from parasites, pesticides, and lack of flowers. Sci. 347, 1255957, https://doi.org/10.1126/science.1255957 (2015).

9. Whitehorn, P. R., Tinsley, M. C., Brown, M. J., Darvill, B. \& Goulson, D. Genetic diversity, parasite prevalence and immunity in wild bumblebees. Proceedings. Biol. sciences/R. Soc. 278, 1195-1202, https://doi.org/10.1098/rspb.2010.1550 (2011).

10. Goulson, D. Review: An overview of the environmental risks posed by neonicotinoid insecticides. J. Appl. Ecol. 50, 977-987, https:// doi.org/10.1111/1365-2664.12111 (2013).

11. van der Sluijs, J. P. et al. Conclusions of the Worldwide Integrated Assessment on the risks of neonicotinoids and fipronil to biodiversity and ecosystem functioning. Environ. Sci. Pollut. Res. Int. 22, 148-154, https://doi.org/10.1007/s11356-014-3229-5 (2015).

12. Woodcock, B. A. et al. Impacts of neonicotinoid use on long-term population changes in wild bees in England. Nat. Commun. 7, 12459, https://doi.org/10.1038/ncomms12459 (2016).

13. Sanchez-Bayo, F. et al. Are bee diseases linked to pesticides? - A brief review. Environ. Int. 89-90, 7-11, https://doi.org/10.1016/j. envint.2016.01.009 (2016).

14. Desneux, N., Decourtye, A. \& Delpuech, J. M. The sublethal effects of pesticides on beneficial arthropods. Annu. Rev. entomology 52, 81-106, https://doi.org/10.1146/annurev.ento.52.110405.091440 (2007).

15. David, A. et al. Widespread contamination of wildflower and bee-collected pollen with complex mixtures of neonicotinoids and fungicides commonly applied to crops. Environ. Int. 88, 169-178, https://doi.org/10.1016/j.envint.2015.12.011 (2016).

16. Blacquiere, T., Smagghe, G., van Gestel, C. A. \& Mommaerts, V. Neonicotinoids in bees: a review on concentrations, side-effects and risk assessment. Ecotoxicol. 21, 973-992, https://doi.org/10.1007/s10646-012-0863-x (2012).

17. Whitehorn, P. R., O'Connor, S., Wackers, F. L. \& Goulson, D. Neonicotinoid pesticide reduces bumble bee colony growth and queen production. Sci. 336, 351-352, https://doi.org/10.1126/science.1215025 (2012).

18. Arena, M. \& Sgolastra, F. A meta-analysis comparing the sensitivity of bees to pesticides. Ecotoxicol. 23, 324-334, https://doi. org/10.1007/s10646-014-1190-1 (2014).

19. Woodcock, B. A. et al. Country-specific effects of neonicotinoid pesticides on honey bees and wild bees. Sci. 356, 1393-1395, https:// doi.org/10.1126/science.aaa1190 (2017).

20. Jin, N., Klein, S., Leimig, F., Bischoff, G. \& Menzel, R. The neonicotinoid clothianidin interferes with navigation of the solitary bee Osmia cornuta in a laboratory test. J. Exp. Biol. 218, 2821-2825, https://doi.org/10.1242/jeb.123612 (2015).

21. Sgolastra, F. et al. Combined exposure to sublethal concentrations of an insecticide and a fungicide affect feeding, ovary development and longevity in a solitary bee. Proceedings of the Royal Society B: Biological Sciences 285, 20180887, 10.1098/rspb.2018.0887 (2018).

22. European Commission. Commission implementing Regulation (EU) No 485/2013 of 24 May 2013 amending Implementing Regulation (EU) No 540/2011, as regards the condition of approval of the active substances clothianidin, thiamethoxam and imidacloprid, and prohibiting the use and sale of seeds treated with plant protection products containing those active substances. Official Journal of the European Union, L139/12 25.5.2013. (2013). 
23. Klatt, B. K., Rundlöf, M. \& Smith, H. G. Maintaining the Restriction on Neonicotinoids in the European Union - Benefits and Risks to Bees and Pollination Services. Frontiers in Ecology and Evolution 4, https://doi.org/10.3389/fevo.2016.00004 (2016).

24. Godfray, H. C. et al. A restatement of the natural science evidence base concerning neonicotinoid insecticides and insect pollinators. Proceedings. Biological sciences/The Royal Society 281, https://doi.org/10.1098/rspb.2014.0558 (2014).

25. Brandt, A. et al. Immunosuppression in Honeybee Queens by the Neonicotinoids Thiacloprid and Clothianidin. Sci. Rep. 7, 4673, https://doi.org/10.1038/s41598-017-04734-1 (2017).

26. Brandt, A., Gorenflo, A., Siede, R., Meixner, M. \& Büchler, R. The Neonicotinoids Thiacloprid, Imidacloprid and Clothianidin affect the immunocompetence of Honey Bees (Apis mellifera L.). J. insect Physiol. 86, 40-47 (2016).

27. Cabrera, A. R. et al. Initial recommendations for higher-tier risk assessment protocols for bumble bees, Bombus spp. (Hymenoptera: Apidae). Integr. Environ. Assess. Manag. 12, 222-229, https://doi.org/10.1002/ieam.1675 (2016).

28. Czerwinski, M. A. \& Sadd, B. M. Detrimental interactions of neonicotinoid pesticide exposure and bumblebee immunity. J. Exp. Zool. Part. A: Ecol. Integr. Physiol. 327, 273-283, https://doi.org/10.1002/jez.2087 (2017).

29. Sánchez-Bayo, F. \& Desneux, N. Neonicotinoids and the prevalence of parasites and disease in bees. Bee World 92, 34-40, https:// doi.org/10.1080/0005772x.2015.1118962 (2015).

30. Di Prisco, G. et al. Neonicotinoid clothianidin adversely affects insect immunity and promotes replication of a viral pathogen in honey bees. Proc. Natl Acad. Sci. U S Am. 110, 18466-18471, https://doi.org/10.1073/pnas.1314923110 (2013).

31. López, J. H. et al. Sublethal pesticide doses negatively affect survival and the cellular responses in American foulbrood-infected honeybee larvae. Scientific reports 7, 40853, 10.1038/srep40853, https://www.nature.com/articles/srep40853\#supplementaryinformation (2017).

32. Alaux, C. et al. Interactions between Nosema microspores and a neonicotinoid weaken honeybees (Apis mellifera). Environ. microbiology 12,774-782, https://doi.org/10.1111/j.1462-2920.2009.02123.x (2010).

33. Ladurner, E., Bosch, J., Kemp, W. \& Maini, S. Assessing delayed and acute toxicity of five formulated fungicides to Osmia lignaria Say and Apis mellifera. Vol. 36 (2005).

34. Scott-Dupree, C. D., Conroy, L. \& Harris, C. R. Impact of currently used or potentially useful insecticides for canola agroecosystems on Bombus impatiens (Hymenoptera: Apidae), Megachile rotundata (Hymentoptera: Megachilidae), and Osmia lignaria (Hymenoptera: Megachilidae). J. economic entomology 102, 177-182 (2009).

35. Biddinger, D. J. et al. Comparative Toxicities and Synergism of Apple Orchard Pesticides to Apis mellifera (L.) and Osmia cornifrons (Radoszkowski). PLoS One 8, e72587, https://doi.org/10.1371/journal.pone.0072587 (2013).

36. Heard, M. S. et al. Comparative toxicity of pesticides and environmental contaminants in bees: Are honey bees a useful proxy for wild bee species? Sci. Total. Environ. 578, 357-365, https://doi.org/10.1016/j.scitotenv.2016.10.180 (2017).

37. Uhl, P. et al. Interspecific sensitivity of bees towards dimethoate and implications for environmental risk assessment. Scientific reports 6, 34439, 10.1038/srep34439 https://www.nature.com/articles/srep34439\#supplementary-information (2016).

38. Sgolastra, F. et al. Synergistic mortality between a neonicotinoid insecticide and an ergosterol-biosynthesis-inhibiting fungicide in three bee species. Pest. Manag. Sci. 73, 1236-1243, https://doi.org/10.1002/ps.4449 (2017).

39. Gradish, A. E. et al. Comparison of Pesticide Exposure in Honey Bees (Hymenoptera: Apidae) and Bumble Bees (Hymenoptera: Apidae): Implications for Risk Assessments. Env. Entomol. 48, 12-21, https://doi.org/10.1093/ee/nvy168 (2019).

40. Cham, K. O. et al. Pesticide Exposure Assessment Paradigm for Stingless Bees. Env. Entomol. 48, 36-48, https://doi.org/10.1093/ee/ nvy137 (2018).

41. Rundlof, M. et al. Seed coating with a neonicotinoid insecticide negatively affects wild bees. Nat. 521, 77-80, https://doi.org/10.1038/ nature14420 (2015)

42. Sgolastra, F. et al. Pesticide Exposure Assessment Paradigm for Solitary Bees. Env. Entomol. 48, 22-35, https://doi.org/10.1093/ee/ nvy105 (2019).

43. EFSA. Scientific opinion on the science behind the development of a risk assessment of plant protection products on bees (Apis mellifera, Bombus spp. and solitary bees). EFSA J10, 2668 (2012).

44. Strachecka, A. et al. Insights into the biochemical defence and methylation of the solitary bee Osmia rufa L: A foundation for examining eusociality development. PLoS one 12, e0176539, https://doi.org/10.1371/journal.pone.0176539 (2017).

45. Frohlich, D. R., Burris, T. E. \& Brindley, W. A. Characterization of glutathione S-transferases in a solitary bee, Megachile rotundata (Fab.) (hymenoptera: megachilidae) and inhibition by chalcones, flavone, quercetin and tridiphane-diol. Comp. Biochem. Physiol. Part. B: Comp. Biochem. 94, 661-665, https://doi.org/10.1016/0305-0491(89)90146-6 (1989).

46. Hertfordshire, U. o. The Pesticide Properties DataBase (PPDB) developed by the Agriculture \& Environment Research Unit (AERU). University of Hertfordshire, 2006-2013 (2013).

47. Sanchez-Bayo, F. \& Goka, K. Pesticide Residues and Bees - A Risk Assessment. PLoS one 9, e94482, https://doi.org/10.1371/journal. pone.0094482 (2014).

48. Rosenkranz, P. et al. DeBiMo-Zwischenbericht. Deutsches Bienenmonitoring (2017).

49. Negri, P. et al. Cellular immunity in Apis mellifera: studying hemocytes brings light about bees skills to confront threats. Apidologie, $1-10$.

50. Evans, J. D. et al. Immune pathways and defence mechanisms in honey bees Apis mellifera. Insect Mol. Biol. 15, 645-656, https://doi. org/10.1111/j.1365-2583.2006.00682.x (2006).

51. Wilson-Rich, N., Dres, S. T. \& Starks, P. T. The ontogeny of immunity: development of innate immune strength in the honey bee (Apis mellifera). J. insect Physiol. 54, 1392-1399, https://doi.org/10.1016/j.jinsphys.2008.07.016 (2008).

52. Tonk, M., Vilcinskas, A. \& Rahnamaeian, M. Insect antimicrobial peptides: potential tools for the prevention of skin cancer. Appl. microbiology Biotechnol. 100, 7397-7405, https://doi.org/10.1007/s00253-016-7718-y (2016).

53. Wilson, E. O. The Insect Societies. (Belknap Press, 1971).

54. Retschnig, G., Neumann, P. \& Williams, G. R. Thiacloprid-Nosema ceranae interactions in honey bees: host survivorship but not parasite reproduction is dependent on pesticide dose. J. invertebrate Pathol. 118, 18-19, https://doi.org/10.1016/j.jip.2014.02.008 (2014).

55. Porrini, C. et al. The death of honey bees and environmental pollution by pesticides: the honey bees as biological indicators. Bull. Insectology 56, 147-152 (2003).

56. Quigley, T. P., Amdam, G. V. \& Harwood, G. H. Honey bees as bioindicators of changing global agricultural landscapes. Curr. Opin. Insect Sci. 35, 132-137, https://doi.org/10.1016/j.cois.2019.08.012 (2019).

57. Authority, E. F. S. Scientific opinion on the science behind the development of a risk assessment of plant protection products on bees (Apis mellifera, Bombus spp. and solitary bees). EFSA J10, 2668 (2012).

58. Vanbergen, A. J. \& Initiative, tI. P. Threats to an ecosystem service: pressures on pollinators. Front. Ecol. Environ. 11, 251-259, https://doi.org/10.1890/120126 (2013).

59. Rasband, W. S. ImageJ. U. S. National Institutes of Health, Bethesda, Maryland, USA, doi:http://imagej.nih.gov/ij/ (1997-2016).

60. Lessells, C. M. \& Boag, P. T. Unrepeatable Repeatabilities: A Common Mistake. Auk 104, 116-121, https://doi.org/10.2307/4087240 (1987). 


\section{Acknowledgements}

We gratefully thank S. Backhaus, B. Barthelmess and D. Brandt for technical support. This research was supported by the EU and Land Hessen "Förderung von Maßnahmen zur Verbesserung der Erzeugung und Vermarktung von Honig in Hessen".

\section{Author contributions}

A.B. and B.H. designed the study and performed the experiments. A.B. and B.H. analysed the data and A.B., F.S., J.B., M.M. and R.B. wrote the manuscript. All authors edited and approved the manuscript.

\section{Competing interests}

The authors declare no competing interests.

\section{Additional information}

Supplementary information is available for this paper at https://doi.org/10.1038/s41598-020-61445-w.

Correspondence and requests for materials should be addressed to A.B.

Reprints and permissions information is available at www.nature.com/reprints.

Publisher's note Springer Nature remains neutral with regard to jurisdictional claims in published maps and institutional affiliations.

(c) (i) Open Access This article is licensed under a Creative Commons Attribution 4.0 International License, which permits use, sharing, adaptation, distribution and reproduction in any medium or format, as long as you give appropriate credit to the original author(s) and the source, provide a link to the Creative Commons license, and indicate if changes were made. The images or other third party material in this article are included in the article's Creative Commons license, unless indicated otherwise in a credit line to the material. If material is not included in the article's Creative Commons license and your intended use is not permitted by statutory regulation or exceeds the permitted use, you will need to obtain permission directly from the copyright holder. To view a copy of this license, visit http://creativecommons.org/licenses/by/4.0/.

(C) The Author(s) 2020 